\title{
Modeling of Reinforced Concrete Beams Exposed to Fire by Using a Spectral Approach
}

\author{
Rui Sun ${ }^{(D)},{ }^{1}$ Bo Xie, ${ }^{1}$ Ricardo Perera ${ }^{(D)},{ }^{2}$ and Yongjun Pan $^{3}$ \\ ${ }^{1}$ Key Laboratory of New Technology for Construction of Cities in Mountain Area, Ministry of Education, \\ School of Civil Engineering, Chongqing University, Chongqing 400045, China \\ ${ }^{2}$ Department of Mechanical Engineering, Technical University of Madrid, José Gutiérrez Abascal 2, 28006 Madrid, Spain \\ ${ }^{3}$ School of Automotive Engineering, Chongqing University, Chongqing 400044, China \\ Correspondence should be addressed to Rui Sun; ruisun@cqu.edu.cn
}

Received 20 February 2018; Accepted 11 June 2018; Published 18 July 2018

Academic Editor: Patrice Berthod

Copyright (c) 2018 Rui Sun et al. This is an open access article distributed under the Creative Commons Attribution License, which permits unrestricted use, distribution, and reproduction in any medium, provided the original work is properly cited.

\begin{abstract}
This paper presents a numerical procedure for predicting the mechanical behavior of reinforced concrete (RC) beams exposed to fire. Thermal behavior is captured using a two-dimensional finite element (FE) model in an environment of elevated temperatures, while a one-dimensional spectral numerical model is formulated to simulate the mechanical response of the beam under increasing loads. Both models are integrated. Previous thermal results obtained from the FE model are provided for the proposed numerical model to calculate the responses of the RC beam for different levels of fire exposure. Few elements are deployed in this study due to the simplicity and efficiency of the proposed numerical model. Consequently, the computational burden of the numerical simulation for predicting the structural performances of RC beams exposed to fire is released comparing with conventional FE model. The numerical results are consistent with the test data, which demonstrate the model's capability of efficiently simulating the thermomechanical behaviors of RC beams due to its simplicity and accuracy.
\end{abstract}

\section{Introduction}

Behavior of RC buildings exposed to fire during their service lifetime is one of the crucial topics that need to be addressed. Degradation of the mechanical properties as well as the residual resistance of RC members is essential for the structural performance under fire [1]. Design codes [2-4] have been developed providing reliable guidelines that can conveniently be employed for the analysis and design of RC structures under fire. They propose simplified expressions empirically obtained from experimental data by means of a standard fire test [5].

As design codes are usually derived from empirical approaches and based on limited experimental results, they are conservative enough from a design point of view. Additionally, they focus on the global behavior of RC members, without addressing possible local phenomena. The constitutive model of concrete, boundary conditions, geometrical configuration, and concrete cracking, which have a significant influence on the performance of RC structures, is not suitably addressed. To understand the mechanical response of materials exposed to fire, experimental tests, in which the residual properties of materials are usually tested after cooling down for the convenience of measurement, are performed $[6,7]$. The results directly illustrate the reduction of mechanical strength of concrete and reinforced steel under high temperatures. However, although the strength capacity of steel can become recovered, the same is not true for concrete. The interfacial bond strength between steel and confined concrete under elevated temperatures reduces even faster than steel according to experimental and numerical studies [8-10], whereas satisfactory accuracy may be achieved using perfect bond assumption for the prediction of global responses of RC structures in an environment of fire or elevated temperatures.

Destructive fire tests have been performed [11-14] to experimentally obtain the residual load-carrying capacity of $\mathrm{RC}$ members, in which RC beams are subjected to standard 
fire tests and loaded to failure as soon as they cool down to room temperature. Many factors influence the degradation of the structural strength or stiffness of RC beams at elevated temperatures, such as support conditions, load level, geometrical properties, and fire scenarios. Thus, the residual strengths of RC members exposed to fire that are experimentally obtained vary over an extensive range due to these uncertainties.

The difficulty of measurement and the cost of experimental tests promote the development of numerical models, which can be conducted as an economical choice for evaluating the residual resistance of RC beams in a nondestructive manner. Simplified cross-sectional analysis has been developed by researchers [15-18]; reduction factors are introduced to strength equations at room temperature to evaluate the residual capacities of RC beams with increasing temperature. However, this methodology may cause the underestimation of the bearing capacities of RC beams since the strain hardening of the reinforcement is not considered. As the most extensively applied numerical method, finite element model is constructed to study the degradation of the structural strengths and residual capacities of RC members exposed to fire. A thermomechanical model that employs a procedure of heat transfer and mechanical response analysis in sequence has been already proposed [19-23]; the temperature-dependent constitutive relationships are utilized to represent the reduction of material properties of concrete and reinforcement at elevated temperatures. The results demonstrate that $\mathrm{FE}$ models are appropriate for predicting the mechanical response of $\mathrm{RC}$ members that are exposed to fire and increasing loads.

Although satisfactory results can be achieved by performing complex FE analyses, the computational costs would undoubtedly increase since a specific constitutive model would be required for each different level of temperature. To overcome this drawback, a two-step simplified approach is presented in this study to predict the structural performance of RC beams exposed to fire. The first step corresponds to a typical thermal analysis performed with a two-dimensional FE model. With this analysis, temperature distribution on the beam is obtained under fire conditions. Subsequently, a one-dimensional spectral element model is developed to perform the mechanical analysis of the RC beam exposed to fire. For it, the beam cross section is divided into several segments with the purpose of including the temperature effects on the material strength throughout the entire cross section. In this way, the mechanical behavior and the degradation of the load-carrying capacity of RC beams after fire exposure can be efficiently evaluated in a nonexpensive way due to the simplicity of the proposed spectral model. The accuracy of the proposed approach is validated by comparing its predictions with experimental tests and more complex FEM analyses published previously [23].

\section{Spectral Element Model for RC Beams}

Although more complex FE models [16, 24-26] have been established to study the mechanical behavior of RC structures at elevated temperatures, one of the main objectives of this study is to develop a simplified numerical approach able to predict the global response of RC beams exposed to fire and simultaneously releasing the computational burden. A one-dimensional spectral element model will be implemented in this study to analyze the mechanical behaviors of RC beams; it will be briefly presented since it has been detailed in $[27,28]$, to simulate RC beams that are externally bonded with fiber-reinforced polymer strips and interfacial debonding damage. First, the interfacial slip between the steel reinforcement and confined concrete is not considered, which indicates that full composite action is assumed to study the global mechanical responses of $\mathrm{RC}$ beams in a simplified way. The coordinates and kinematic of the transverse section of RC beam are shown in Figure 1, and the axial and transverse displacements of a beam can be expressed using first-order shear deformation theory:

$$
\begin{aligned}
& u_{\mathrm{C}}(x, z, t)=u_{0}(x, t)-z \phi(x, t), \\
& w(x, z, t)=w(x, t),
\end{aligned}
$$

where $u_{0}$ and $u_{\mathrm{C}}$ are the axial displacement at midplane and a certain point with a depth of $z$ from midplane, respectively, and $w$ and $\phi$ denote the transverse displacement and rotation of the cross section about the $y$-axis. The stress of the concrete and steel bars can be formulated according to the perfect bond assumption as follows:

$$
\begin{array}{ll}
\sigma_{\mathrm{C}}=E_{\mathrm{C}} \varepsilon_{\mathrm{C}}, & \varepsilon_{\mathrm{C}}=u_{0, x}-z_{\mathrm{C}} \phi_{, x}, \\
\sigma_{\mathrm{B}}=E_{\mathrm{B}} \varepsilon_{\mathrm{B}}, & \varepsilon_{\mathrm{B}}=u_{0, x}-z_{\mathrm{B}} \phi_{, x}, \\
\tau_{\mathrm{C}}=G_{\mathrm{C}} \gamma_{\mathrm{C}}, & \gamma_{\mathrm{C}}=w,_{x}-\phi,
\end{array}
$$

where $\sigma$ and $\tau$ represent the axial stress and shear stress; the subscripts $\mathrm{C}$ and $\mathrm{B}$ represent the concrete and steel bars, respectively; $\varepsilon_{C}$ and $\varepsilon_{B}$ are the longitudinal strain of concrete and the longitudinal strain of the bars derived from (1) with the coordinates $z_{\mathrm{C}}$ and $z_{\mathrm{B}}$, respectively; and the elastic modulus of concrete and steel reinforcement $E_{\mathrm{C}}$ and $E_{\mathrm{B}}$ and shear modulus of concrete $G_{C}$ are highly dependent on the stressstrain constitutive relationship, which would change significantly with the variation of temperature.

Using Hamilton's principle, the differential equation of motion, which is related to the variables $u_{0}, w$, and $\phi$, can be derived based on the following expression:

$$
\begin{aligned}
\delta u_{0}: I_{0} \ddot{u}_{0}-I_{1} \ddot{\phi}-A_{11} u_{0, x x}+B_{11} \phi_{, x x} & =0, \\
\delta w: I_{0} \ddot{w}-A_{22} w_{, x x}+A_{22} \phi_{, x} & =0, \\
\delta \phi: I_{2} \ddot{\phi}-I_{1} \ddot{u}_{0}+B_{11} u_{0, x x}-D_{11} \phi_{, x x}-A_{22} w_{, x}+A_{22} \phi & =0 .
\end{aligned}
$$

The boundary force equations are expressed as

$$
\begin{aligned}
N & =A_{11} u_{0, x}-B_{11} \phi_{, x}, \\
V & =A_{22} w_{, x}-A_{22} \phi, \\
M & =-B_{11} u_{0, x}+D_{11} \phi_{, x},
\end{aligned}
$$

where $N, V$, and $M$ are the boundary forces associated with $u_{0}, w$, and $\phi$, respectively; ( $)_{x}$ and (.) represent the differentiation with respect to length and time; $A_{11}, B_{11}, D_{11}$, and $A_{22}$ are the stiffness coefficients defined by the material properties; and $I_{0}, I_{1}$, and $I_{2}$ are related to the inertial items. 


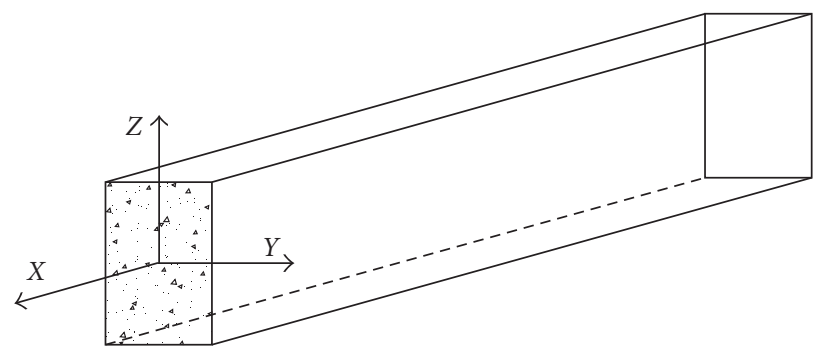

(a)

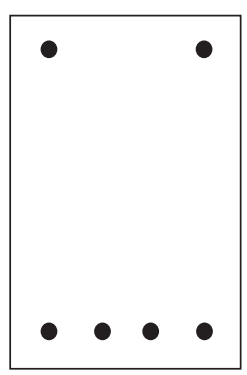

(b)

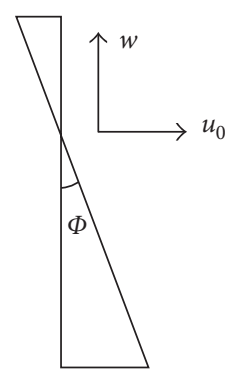

Figure 1: Coordinates and kinematic of the transverse section of RC beam.

Unlike the conventional FE model, one of the main differences of the proposed spectral element method (SEM) is the implementation of a fast Fourier transform (FFT), which is capable of transferring the displacement field from the time domain to the frequency domain. The three variables are formulated as

$$
\left\{u_{0}, w, \phi\right\}==\sum_{n=1}^{N} \sum_{m=1}^{M}\left\{\widehat{u}_{m n}^{*}\right\} e^{-j k_{m n} x} e^{-j \omega_{n} t},
$$

where $\omega_{n}$ denotes circular frequency at the $n$th sampling point, and $k_{m n}$ is the $m$ th wave number related to $\omega_{n}$ in FFT. $\left\{\widehat{u}_{m n}^{*}\right\}=\left(\widehat{u}_{0}, \widehat{w}, \widehat{\phi}\right)_{m n}$ represents the vector of wave coefficients related to the $m$ th mode of the wave at the frequency point $\omega_{n}$. By introducing (6), governing equations (4) turn into the following formula:

$$
[W]\left\{\widehat{u}^{*}\right\}=0,
$$

where $W$ is a matrix with $3 \times 3$ dimensions in function of frequency and wave number as follows:

$$
[W]=\left(\begin{array}{ccc}
A_{11} k^{2} & 0 & -B_{11} k^{2}+I_{1} \omega_{n}^{2} \\
0 & A_{22} k^{2}-I_{0} \omega_{n}^{2} & -j A_{22} k \\
-B_{11} k^{2}+I_{1} \omega_{n}^{2} & j A_{22} k & D_{11} k^{2}-I_{2} \omega_{n}^{2}+A_{22}
\end{array}\right) .
$$

For each frequency point, the wave number $k_{m n}$ can be obtained by solving a 6th order equation when $W$ equals zero in (8), and the six related eigenvectors $R_{i}(i=1, \ldots, 6)$ can be used to formulated the general solution of nodal displacement as

$$
\begin{aligned}
\{u(x)\} & =\left(\begin{array}{c}
\hat{u}_{0}(x) \\
\hat{w}(x) \\
\hat{\phi}(x)
\end{array}\right) \\
& =\left[\left\{R_{1}\right\} \cdots\left\{R_{6}\right\}\right] \underset{i=1, \ldots, 6}{\operatorname{diag}}\left(e^{-j k_{i} x}\right)\{A\} \\
& =[R][D(x)]\{A\} .
\end{aligned}
$$

Furthermore, the displacements of two nodes in an element with the length of $L$ can be expressed as

$$
\left\{\begin{array}{l}
u_{1} \\
u_{2}
\end{array}\right\}=\left[\begin{array}{l}
R_{1} \\
R_{2}
\end{array}\right]\left[\begin{array}{l}
D(0) \\
D(L)
\end{array}\right]\{A\}=\left[T_{1}\right]\{A\},
$$

where $\{A\}$ is the vector of constants which depends on the associated boundary conditions. Substituting (10) into (9), the solutions of nodal displacements can be obtained as

$$
\{u(x)\}=[R][D(x)]\left[T_{1}\right]^{-1}\left\{\begin{array}{l}
u_{1} \\
u_{2}
\end{array}\right\}=[N]\left\{\begin{array}{l}
u_{1} \\
u_{2}
\end{array}\right\},
$$

where $[N]$ is the matrix of shape functions of the proposed spectral model. By combining boundary force equations (5), the dynamic stiffness matrix (DSM) $[K]$ is obtained to calculate the displacement in frequency field:

$$
\left\{\begin{array}{l}
\left\{f_{1}\right\} \\
\left\{f_{2}\right\}
\end{array}\right\}=\left[\begin{array}{l}
F(0) \\
F(L)
\end{array}\right]\{A\}=\left[T_{2}\right]\left[T_{1}\right]^{-1}\left\{\begin{array}{l}
u_{1} \\
u_{2}
\end{array}\right\}=[K]_{6 \times 6}\left\{\begin{array}{l}
u_{1} \\
u_{2}
\end{array}\right\} .
$$

Because the governing equations and boundary conditions were previously derived in the frequency domain, the DSM in (12), which is frequency-dependent, can be established. Compared with the conventional FE model, the DSM may be considered as a combination of a mass matrix and a stiffness matrix using exact dynamic shape functions, which are obtained according to the governing differential equations. Considering the variation in the DSM, which depends on frequency, one spectral element sufficiently represents a structure as long as its material and geometrical properties remain uniform throughout the entire element, which indicates that the mesh refinement in a highfrequency range is no longer necessary leading to significant reduction of the degree of freedom and computational costs. Therefore, the mechanical behaviors of a structure can be captured in a fast way with a very small number of elements due to its simplicity and efficiency. The static behaviors of RC beams can be directly calculated by making frequency value in DSM tend to zero to prevent numerical problems in this study. Details of the proposed model can be checked in $[27,28]$. The temperature-dependent material constitutive model is discussed in Section 4.

\section{Transient Thermal Analysis of RC Beams}

In this study, a thermomechanical analysis of RC beams is performed in two steps: firstly, a thermal analysis and secondly, a mechanical analysis. Temperature distributions obtained in the first step will be taken as a basis for a subsequent mechanical analysis. To simplify the thermal analysis, the air temperature 
has been assumed spatially homogeneous, and the longitudinal thermal transfer along the length of beam has been disregarded. Furthermore, in this study, concrete is treated as homogeneous material which is represented by a stress-strain relationship. According to this assumption, the thermal distribution would be uniform along the length of the RC beam, since the nonuniform distribution of components of concrete (e.g., cement and aggregates) is neglected in a macroscopic perspective. Hence, a $2 \mathrm{D}$ transient thermal analysis throughout a typical cross section is representative for predicting the temperature distribution, which varies along the length of the RC beam similarly, and the thermal problem is reduced to a $2 \mathrm{D}$ problem as in $[29,30]$.

When a structure is exposed to fire, convection, radiation, and conduction phenomena must be considered. While convection and radiation involve heat flux through the surface of the structure, conduction involves heat transfer through the body of structure. The three phenomena should be appropriately considered in a transient thermal analysis, in which heat conduction is governed using partial differential equations [1] as

$$
\frac{\partial}{\partial x}\left(k \frac{\partial T}{\partial x}\right)+\frac{\partial}{\partial y}\left(k \frac{\partial T}{\partial y}\right)+\frac{\partial}{\partial z}\left(k \frac{\partial T}{\partial z}\right)+Q-\rho c \frac{\partial T}{\partial t}=0
$$

where $T$ is the temperature distribution with respect to $x y z$ coordinate, $\rho$ is the material density, and $k$ and $c$ represent the thermal conductivity and specific heat, respectively, which are highly temperature-dependent. The specific volumetric heat source $Q$ equals zero since no inherent heart source exists in this case. The initial temperature is needed to solve the differential equation, which can be identified as the ambient temperature at the beginning of the fire test. The effect of heat convection and radiation can be considered using the following surface boundary condition:

$$
-k \frac{\partial T}{\partial n}=h_{\mathrm{c}}\left(T-T_{\mathrm{f}}\right)+\sigma \varepsilon_{\mathrm{m}} \varepsilon_{\mathrm{f}}\left[\left(T-T_{\mathrm{z}}\right)^{4}-\left(T_{\mathrm{f}}-T_{\mathrm{z}}\right)^{4}\right],
$$

where $n$ represents the normal direction of the outside surface, $h_{c}$ is the coefficient of convective heat transfer, which is expressed as $25 \mathrm{~W} /\left(\mathrm{m}^{2} \cdot \mathrm{K}\right), \sigma=5.67 \times 10^{-8} \cdot \mathrm{W} /\left(\mathrm{m}^{2} \cdot \mathrm{K}^{4}\right)$ denotes the Stefan-Boltzmann constant, $\varepsilon_{\mathrm{m}}$ and $\varepsilon_{\mathrm{f}}$ are the surface emissivity of a structure and the surface emissivity of fire, respectively, and $T_{\mathrm{f}}$ and $T_{\mathrm{z}}$ represent the temperature measured at the fire-exposed surface of a structure and the absolute zero temperature, respectively.

In this study, a 2D FE model of a typical cross section of an RC beam will be established using commercial FEM software, and the ambient temperature of a furnace during the fire test will be directly applied to the surface of an RC beam as thermal loads according to ISO 834 guidelines [5] to perform the transient thermal analysis. Considering that the steel reinforcement only takes a small part in the cross section of the beam, the temperature differences between concrete and steel bars can be ignored [31]. Therefore, the reinforcement will be disregarded in the transient thermal analysis for simplicity. The temperature distribution will be

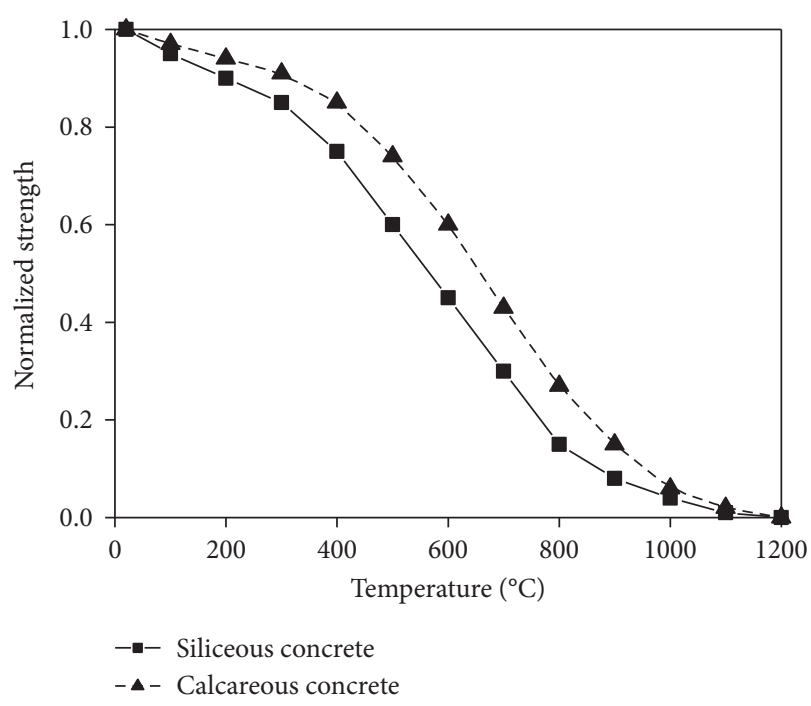

FIGURE 2: Normalized compressive strength of concrete at elevated temperatures.

employed to predict the structural behaviors of the RC beam in the next step.

\section{Temperature-Dependent Material Properties}

The suitable specification of the material properties highly dependent on the temperature is essential in the numerical simulation due to their influence on the thermal and mechanical responses of RC beams exposed to fire. The relationships provided in the European code [2] will be implemented in this study. The density of concrete does not significantly change at elevated temperatures (less than 5\%) $[32,33]$, and it usually has a minor influence on thermal responses. Thus, a constant value of $2300 \mathrm{~kg} / \mathrm{m}^{3}$ will be assumed in this study. The conductivity $k$ and specific heat $c$ of concrete in (13) can be expressed as functions of temperature according to European code [2]:

$$
\begin{aligned}
& k=1.6-0.16 \frac{T}{120}+0.008\left(\frac{T}{120}\right)^{2}, \\
& c=900+80 \frac{T}{120}-4\left(\frac{T}{120}\right)^{2} .
\end{aligned}
$$

Since the steel reinforcement has a minor influence on the heat conduction analysis, its thermal properties are not considered.

The variation in the mechanical properties of concrete and reinforcement has been specified according to many experimental tests and design guidelines. The Eurocode model [2] is deployed to describe the uniaxial compressive constitutive model of concrete at evaluated temperatures. The compressive strength $f_{\mathrm{c}}$ and the related strain $\varepsilon_{\mathrm{c} 1}$ are expressed as a function of temperature since these critical parameters define the stressstrain relationship of concrete for a given temperature. As shown in Figure 2, a higher temperature would undoubtedly cause a reduction of compressive strength of concrete, and its corresponding strain would increase as illustrated in [2]. The linear stress-strain relationship of compressive concrete is 


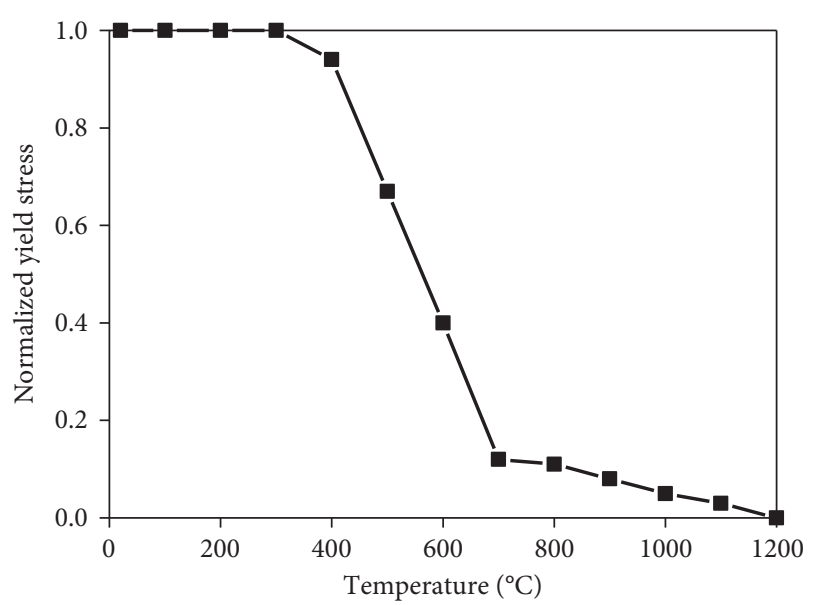

FIGURE 3: Normalized yield stress of steel at elevated temperatures.

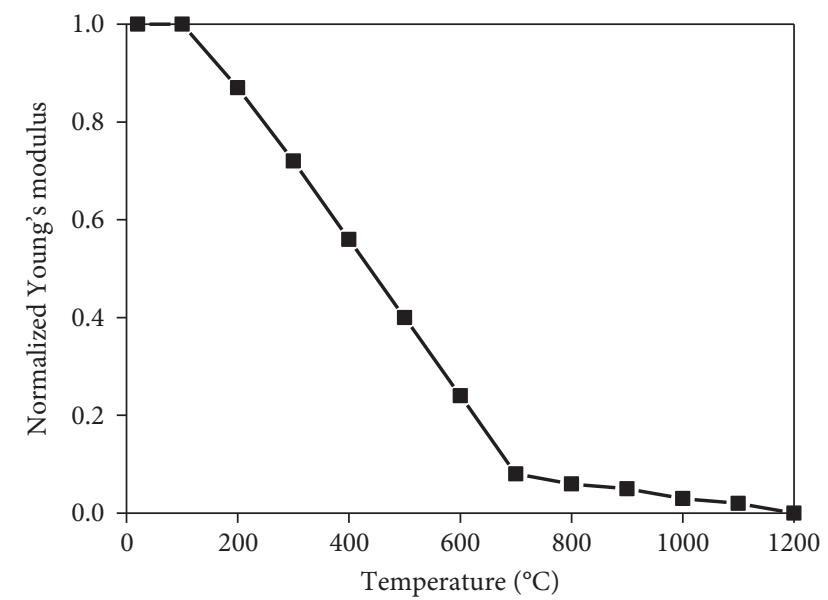

Figure 4: Normalized Young's modulus of steel at elevated temperatures.

assumed until $0.33 f_{\mathrm{c}}$ is attained. Then, a nonlinear increase in compressive stress is adopted with the development of concrete strain to represent the strain-hardening curve to the compressive strength $f_{c}$, which can be expressed as

$$
\begin{aligned}
\sigma_{\mathrm{c}} & =\frac{3 \eta}{2+(\eta)^{3}}, \\
\eta & =\frac{\varepsilon_{\mathrm{c}}}{\varepsilon_{\mathrm{cl}}}
\end{aligned}
$$

where $\sigma_{\mathrm{c}}$ and $\varepsilon_{\mathrm{c}}$ denote the concrete stress and the related strain, respectively. A linear descending branch is used to represent the postpeak softening behavior of concrete based on the ultimate strain in compression, in which empirical values are recommended in [2]. A bilinear stress-strain relationship is used to represent the concrete behavior in tension with a linear ascending up to the tensile strength $f_{\mathrm{ct}}$. The value of $f_{\mathrm{ct}}$ decreases to zero with the increase in temperature up to $600^{\circ} \mathrm{C}$ as presented in [2], and some modifications are introduced to avoid the numerical problem of simulation [34]. The linearly descending branch is defined based on the ultimate strain in tension $\varepsilon_{\mathrm{ct}}$ whose value does not depend on temperature and fall between 0.002 and 0.004 according to Terro [35].

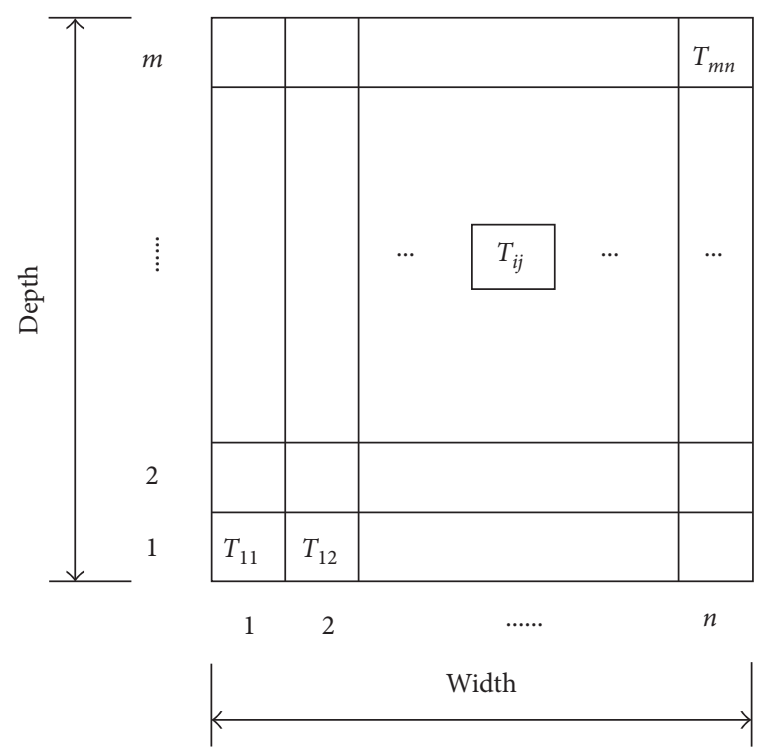

Figure 5: Discretization of cross section for structural analysis.

Figures 3 and 4 illustrate the reduction of yield stress and Young's modulus of steel at elevated temperatures, respectively. The mechanical properties of steel reinforcement are defined by Eurocode 2 [2], in which a set of empirical formulas were concluded to represent the temperature reduction of constitutive relationships.

Besides, one of the critical points is the modeling of bond-slip behavior between steel reinforcement and concrete. In this study, a perfect bond performance is assumed, which represents that the average strain in the reinforcement equals to that of the concrete at the same location. This assumption is able to represent compressive section of RC beams accurately. While in the tensile section, the appearance of cracks might cause weakness of bond performance leading to a slipping of reinforcement. However, since a smeared crack model is employed in the proposed spectral approach, in which one element would be enough to model an entire segment as long as the geometrical and material properties remain to be constant, and the cracking process is simulated by specifying the reduction of concrete strength using constitutive equations. According to this, the average strain of steel and concrete at the same location is approximately the same since no stress concentration is presented by using the smeared crack model. Thus, a perfect bond behavior between concrete and reinforcement is deemed to be adequate in this study for simplicity.

\section{Framework to Evaluate the Fire Performances of RC Beams}

In the first stage, the temperature distribution along the time is computed by performing a transient thermal analysis on a 2D FE model of the beam cross section since the longitudinal heat transfer is disregarded. The heat transfer coefficients presented in Section 3 will be used.

As long as the temperature distribution has been obtained at one thermal load step, the spectral element model 


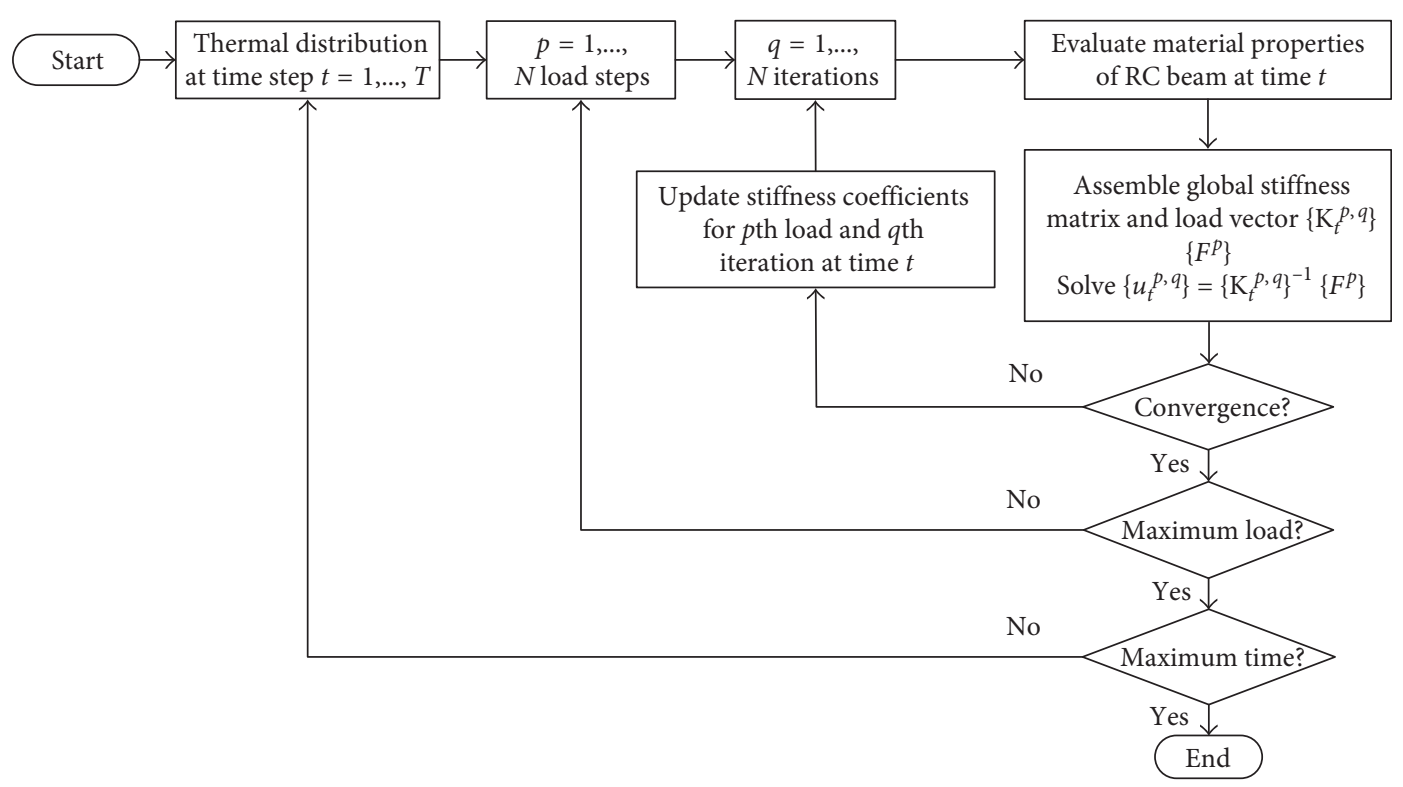

FIGURE 6: Framework of proposed numerical strategy.

presented in Section 2 will be implemented to simulate the mechanical responses of RC beams due to the simplicity and low time consumption of the proposed one-dimensional model. The temperature distribution of the cross section obtained at a given thermal load step will be utilized to update the constitutive equations of concrete and steel reinforcement based on Eurocode 2 [2]. The cross section has been divided into $m \times n$ layers along the depth and width of the RC beam, as shown in Figure 5, and the temperature in each block is assumed to remain constant to simplify the process of structural analysis. The temperature of each element $T_{i j}$ can be approximately evaluated by averaging the temperatures of four nodes of the element according to the temperature distribution of the cross section provided at a transient time. Thus, the temperature-dependent material properties of each block can be obtained according to the average temperature $T_{i j}$ at its location by applying the empirical equations in Eurocode 2. They will be applied to determine the stiffness matrix of the $\mathrm{RC}$ beam based on the proposed spectral model.

To describe the procedure of numerical analysis in detail, a flowchart of the proposed strategy is illustrated in Figure 6. At the beginning, the thermal distribution of a specimen under a fire scenario is evaluated by using a 2D FE model, and the external forces are applied to the RC beam with gradually increased loading steps as the temperature distribution remains constant. Thus, the problem of the fire performance of an RC beam has been transferred to a structural analysis with a new stress-strain relationship that has been updated by a given thermal distribution, and the proposed one-dimensional spectral model will be deployed to predict the mechanical behaviors of the RC beam.

In the structural analysis, when the applied loadings are at low level, the elastic moduli of concrete and reinforcement remain available for calculation. However, the nonlinear behaviors of materials would occur with the increase in load. This phenomenon is simulated by using equivalent secant elastic moduli for concrete and steel reinforcement, which would be simultaneously updated with the development of local strain. Hence, the parameters $A_{11}, B_{11}, D_{11}$, and $A_{22}$ of DSM in (12) that related to tangent elastic moduli are no longer constant but in function of strain at every point. During the updating process, the temperature-dependent constitutive relations are defined by empirical formulas of Eurocode for each temperature scenario provided by the previous transient thermal analysis. As previously mentioned, the strain of steel bar equals the strain of concrete at the same location since perfect bond performance is assumed in this study. According to this, the DSM is implicitly updated to simulate the progressive cracking of concrete during iterations until force equilibrium is reached. Consequently, the displacement vector of structure is obtained under one fire scenario, and the same procedure can be performed for the next thermal step.

Following the numerical approach illustrated in Figure 6, the process of calculation is performed in an implicit manner to obtain the nodal displacement vector and the related loadcarrying capacity by the iterative procedure until convergence is achieved. By doing this, the structural responses can be evaluated by gradually increasing the load on the RC beam until failure occurs after fire exposure. Alternatively, the mechanical behaviors can also be determined under a given load with the development of time-temperature exposure.

\section{Validation of the Proposed Numerical Method}

6.1. Experimental Tests. To validate the accuracy and capability of the proposed numerical method for the structural analysis of an RC beam under fire exposure, experimental tests performed by Kumar and Kumar [12] were taken as a reference. In Kumar's tests, a set of RC beams were cast to study their structural performance when exposed to fire with 


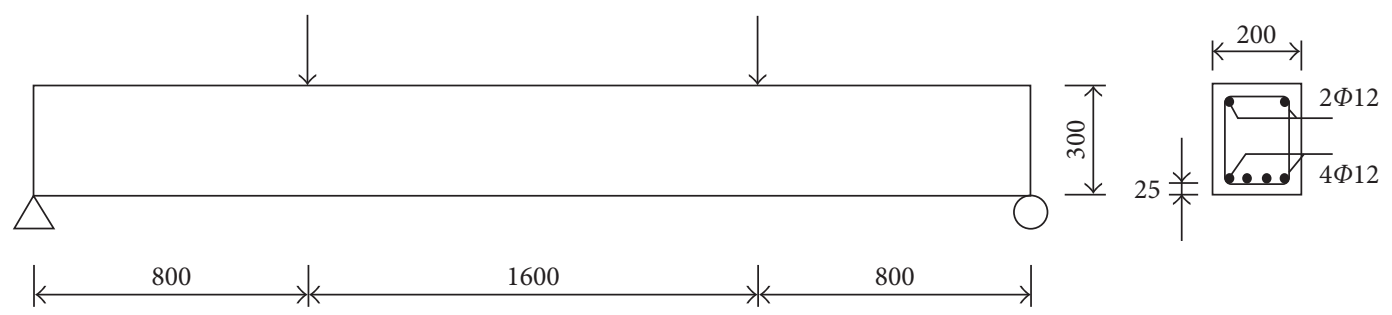

FIgURE 7: Experimental test setup.

variable duration. The width, depth, and length of the reinforced beams were $200 \mathrm{~mm}, 300 \mathrm{~mm}$, and $3950 \mathrm{~mm}$, respectively, while the span between supports was $3200 \mathrm{~mm}$. Four-point loading was progressively applied to the beam with a shear span of $800 \mathrm{~mm}$; the experimental setup is shown in Figure 7. The material and geometrical properties of the specimens are illustrated in Table 1.

Four specimens were selected to perform fire tests in a furnace with a constant ambient temperature of $20^{\circ} \mathrm{C}$ at the top surface of the beams, whereas the bottom and two lateral sides were exposed to the following temperature-time relationship according to ISO 834 standard:

$$
T(t)=T\left(t_{0}\right)+345 \log (8 t-1),
$$

where $T\left(t_{0}\right)$ denotes the initial ambient temperature $\left(20^{\circ} \mathrm{C}\right)$. They are exposed to fire for $1,1.5,2$, and 2.5 hours. The ambient temperature remains at $20^{\circ} \mathrm{C}$ as the specimens cool down, and the four-point loading tests were performed on these specimens including one unheated reference beam up to failure in order to check their residual resistances. Two loading platens were employed to control the deflection of RC beams during the tests. Only experimental data of the four specimens (reference beam and beam exposed to fire for $1,1.5$, and 2 hours) are available because the beam with 2.5 hours of fire exposure failed to be tested due to spalling of concrete after cooling down.

A 3D FE model was developed by Ozbolt in [23] to study the mechanical behavior of RC beams tested by Kumar and Kumar in [12]. In his work, a transient three-dimensional thermomechanical model was implemented into a threedimensional FE code, and it was performed under a framework of continuum mechanics and irreversible thermodynamics. The constitutive law of concrete is the temperature-dependent microplane model whereas the mechanical properties would not influence the thermal distribution. Besides, damage and cracking is simulated by applying smeared crack model. The numerical prediction of the more complex FE model agrees quite well with experimental results. Thus, they will be used to validate the efficiency of the simplified spectral model.

6.2. Results and Discussion. As presented in the previous section, this study has two main steps, including transient thermal and structural analysis. The beams were exposed to elevated temperatures on three sides (bottom and two lateral faces) in the fire tests; thus, the thermal distribution of an RC beam can be evaluated by implementing an FEM analysis at each time step. In the FE model, the element size was chosen to be $5 \mathrm{~mm}$ resulting in 60 elements along the depth cross
TABLE 1: Material and geometrical properties of specimens.

\begin{tabular}{lcc}
\hline & \multicolumn{1}{c}{ Specimens } \\
\hline \multirow{3}{*}{ Concrete } & Elastic modulus (MPa) & 19,600 \\
& Compressive strength (MPa) & 17.10 \\
& Tensile strength (MPa) & 2.00 \\
\hline \multirow{3}{*}{ Steel bar } & Diameter (mm) & 12 \\
& Yield stress (MPa) & 480 \\
& Ultimate strength & 550 \\
RC beam & Span (mm) & 3200 \\
& Width (mm) & 200 \\
& Height (mm) & 300 \\
\hline
\end{tabular}

section, and thermal loads are applied on the bottom and two lateral surfaces. By doing this, the temperature distribution throughout the entire cross section can be evaluated. In order to validate the accuracy of proposed $2 \mathrm{D}$ FE model, the numerical thermal results should be compared with measured experimental data; however, the thermal data of experimental tests were not presented in [12]. To solve this problem, the experimental thermal results measured from [22] were selected to compare the numerical thermal results in this work, for the reason that the geometrical and material properties of $\mathrm{RC}$ beams used in [12] and [22] are very similar. Therefore, the numerical and experimental results in the middle layer of the RC beam at different depths of 10,25 , and $100 \mathrm{~mm}$ are compared in Figure 8, and the numerical results have to be found to be in close agreement with existing test results.

To further understand the thermal responses of an RC beam, temperature distributions along different levels of depth at $0.5,1,1.5$, and 2 hours fire exposure are illustrated in Figure 9, and the numerical results are similar to the data obtained in the literature [22]. The temperature in each block of the cross section shown in Figure 5 can be calculated by taking the average temperature of the four nodes of the element. Nonlinear stress-strain relationships of concrete and steel reinforcement at any locations of the cross section are able to be identified according to the obtained thermal data. After that, a structural analysis is performed using the proposed spectral model, and the numerical simulation follows the framework described in Figure 6.

According to the formulation of proposed spectral model, one element is enough to represent a section as long as no discontinuity of geometrical and material properties exists throughout the entire segment. In this study, in order to capture the mechanical behaviors of the RC beam with the increase in load under different fire scenarios, more accurate results would be achieved by applying more spectral elements since the progressive degradation of the RC beam due 


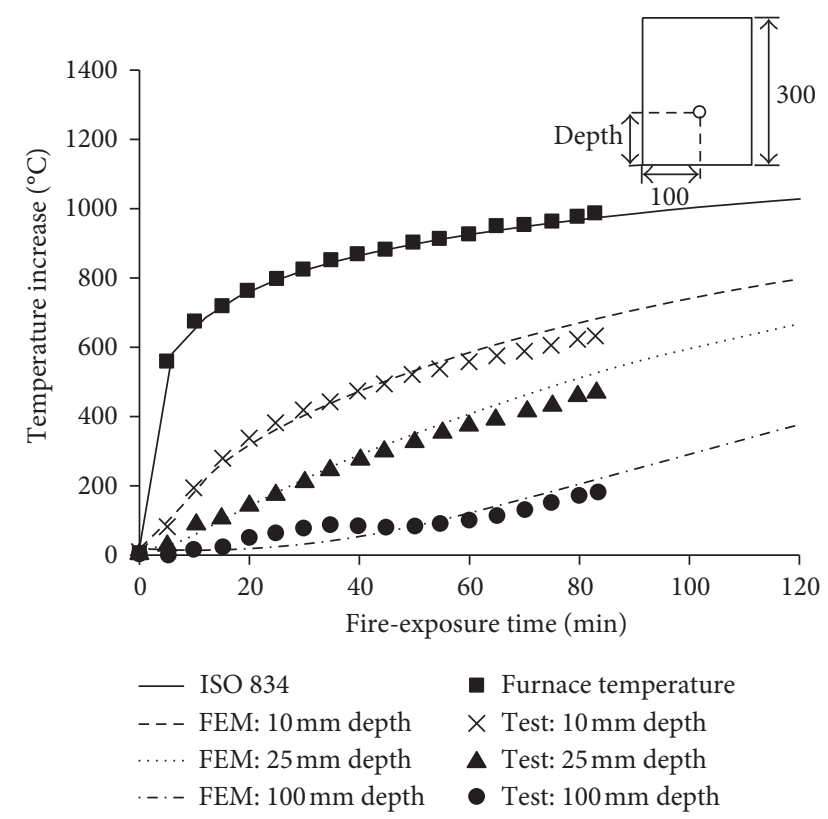

FIgURE 8: Temperatures evaluated by FEM at various locations with fire duration.

to material nonlinearities can be simulated more appropriately with a finer mesh. If more elements were applied, the precision of numerical results would be higher, but the increment may not compensate the remarkable increment in the computational burden. Therefore, the number of elements can be defined by searching a balance between accuracy and computational costs according to the desired degree of precision.

Here, an element size of the proposed spectral model of $200 \mathrm{~mm}$ is selected for the structural analysis resulting in only 16 spectral elements in this study to simulate the mechanical behavior of RC beams with a length of $3.2 \mathrm{~m}$. Thus, the computational costs are significantly reduced compared with the conventional FE model. To validate the accuracy of the proposed numerical approach, the numerical results of an RC beam for four fire scenarios (no heating and heating after $1,1.5$, and 2 hours) are illustrated in Figures 10(a)-10(d) to compare with the results of the experimental tests and FE analysis.

The load-deflection curve of the reference beam is shown in Figure 10(a), and the numerical results correspond quite well with the results of the experimental tests and FE model. Concrete cracking and the subsequent steel yielding occur at the loading points of $50 \mathrm{kN}$ and $150 \mathrm{kN}$. The cracking loads of the RC beams after $1 \mathrm{~h}, 1.5 \mathrm{~h}$, and $2 \mathrm{~h}$ decreased to 40,35 , and $30 \mathrm{kN}$ according to the numerical results predicted by the proposed model, as shown in Figures 10(b)-10(d). This is attributed to the loss of concrete strength with the increase in temperature. The steel yields loading are 140,110 , and $70 \mathrm{kN}$ for the three fire scenarios, which demonstrate the reduction of steel strength exposed to thermal loads. The numerical results indicate agreement with the experimental tests and FE model in Figures 10(a)-10(c). As shown in Figure 10(d), a comparatively large difference exists between the proposed model and the FE model after $2 \mathrm{~h}$ of fire exposure. This might

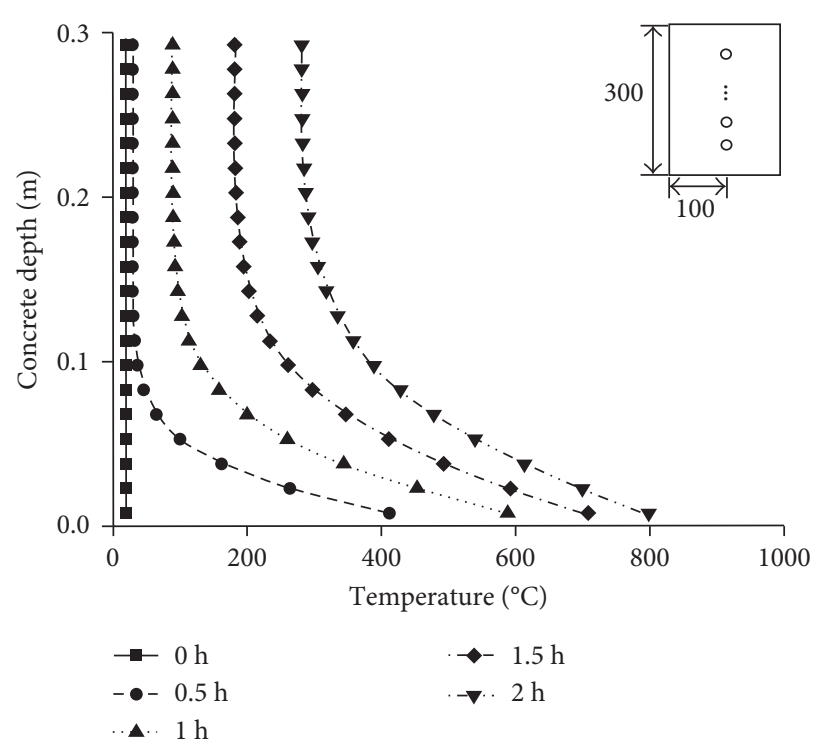

FIgure 9: Temperature distributions over concrete depth at the central layer of midspan with fire duration.

be attributed to the fact that the interfacial bond behavior between concrete and reinforcement can be appropriately modeled by applying FEM, and it would significantly influence the global structural performances under elevated temperatures. In this study, the reinforcement is assumed to be perfectly bonded to the concrete. This assumption is appropriate to predict the degradation of load-carrying capacity of an RC beam exposed to fire taking into account that the deterioration of material strength is the critical factor, and the proposed one-dimensional numerical model is established to perform the structural analysis according to the simplification. Despite this, the loss of precision can be compensated by the efficiency of the proposed spectral model since one of the main objectives is to model the mechanical behaviors of the RC beam under fire exposure in an efficient way.

In the proposed spectral approach, the nonlinear behavior of the material is introduced by using equivalent secant elastic modulus which would be updated implicitly during iteration. To avoid convergence difficulties, the external load is divided into load levels, and an iterative secant procedure is performed to search the solution until force equilibrium is achieved for each load level as illustrated in Figure 6. According to this load-control strategy, the nodal displacement would increase with the increase in load, and consequently, convergence would be failed to achieve as long as applied load exceeds the bearing capacity of the RC beam. Therefore, monotonic increase in bearing capacity can be observed in Figure 10 because of the implementation of load-control strategy in this study. In spite of this, the accuracy of numerical results can be considered to be satisfactory since a limited number of elements were employed in the proposed model. Hence, the proposed spectral model is appropriate for determining the mechanical behaviors of RC beams exposed to fire.

To gain a better understanding of the structural deformation of RC beams after fire exposure, the midspan 


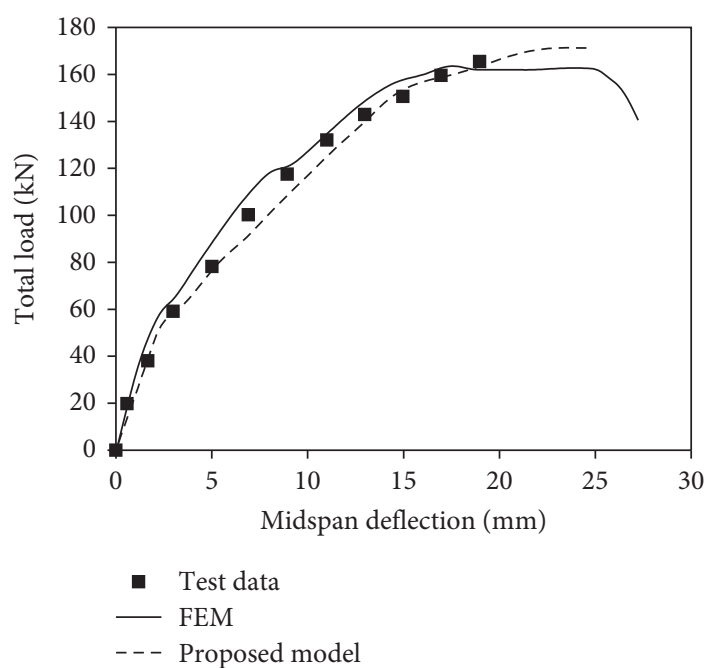

(a)

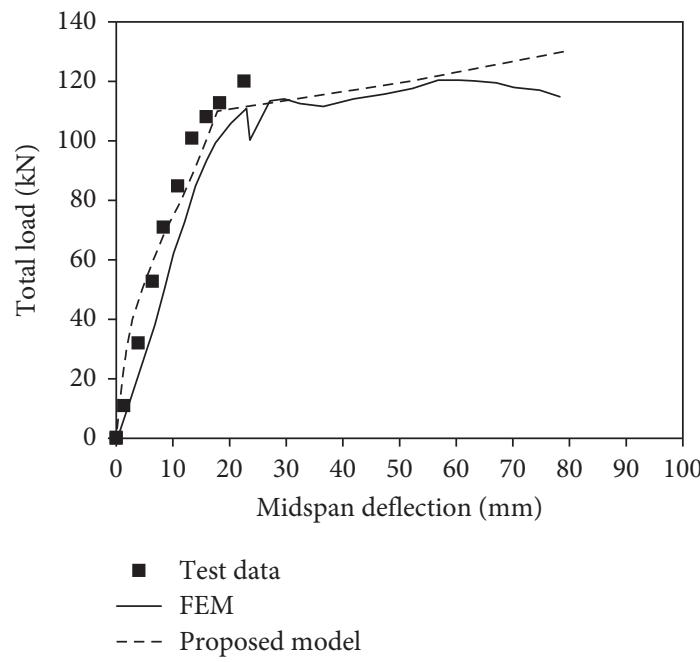

(c)

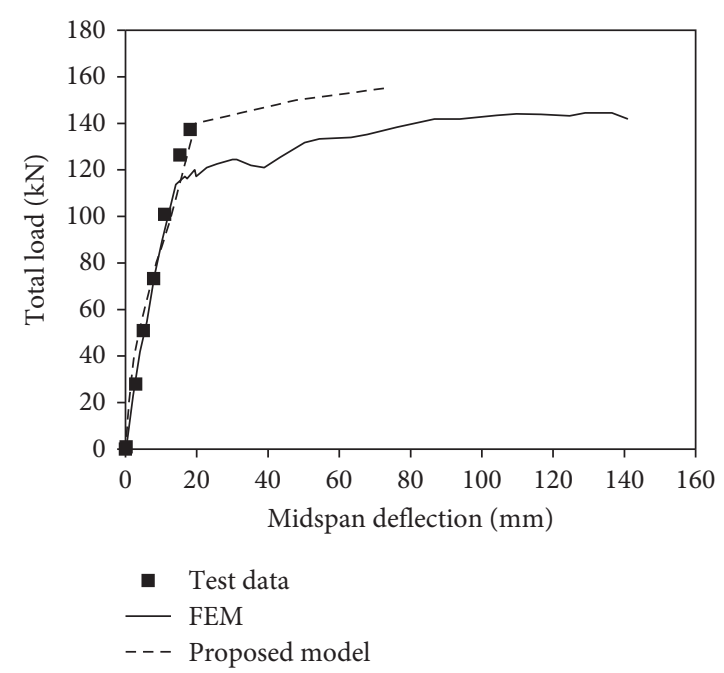

(b)

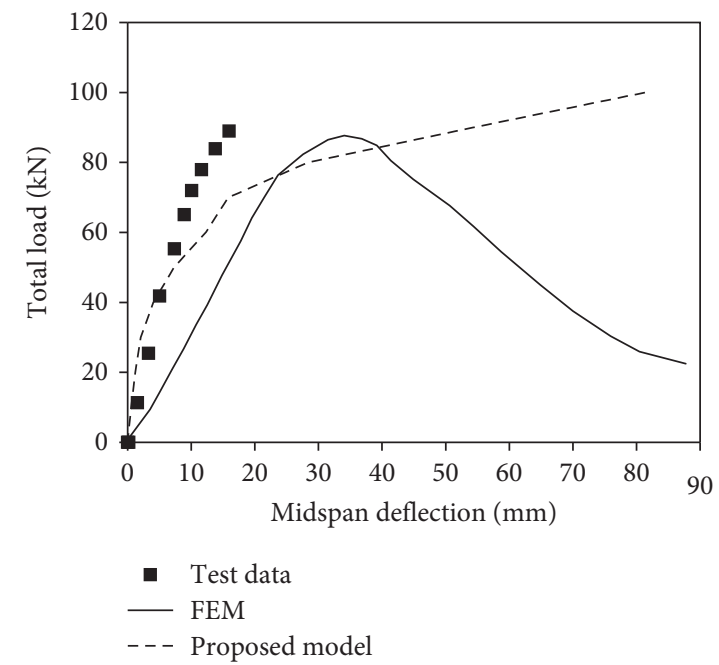

(d)

FIgURE 10: Load-midspan deflection (a-d): reference beam; fire exposure duration of $1 \mathrm{~h}, 1.5 \mathrm{~h}$, and $2 \mathrm{~h}$.

deflections under external loadings of 60,70 and $80 \mathrm{kN}$ are illustrated in Figures 11(a)-11(c). With the development of fire exposure, the experimental results exhibit large midspan displacements, which increase from 3.1, 4.2 and $5.1 \mathrm{~mm}$ after $0 \mathrm{~h}$ of fire exposure to $8.1,10$ and $12.5 \mathrm{~mm}$, respectively, after $2 \mathrm{~h}$ of fire exposure for the three loading scenarios. As expected, the same phenomena can be observed from the results of the FEM analysis and proposed numerical approach, which clearly demonstrate the reduction of resistance capacity of RC beams under thermal loads. A sharp increase in midspan deflections is observed from $1.5 \mathrm{~h}$ to $2 \mathrm{~h}$ fire duration according to the proposed model and the FEM. This is mainly due to the rapid loss of steel strength as long as temperature reached $600^{\circ} \mathrm{C}$, as shown in Figures 3 and 4 . As illustrated in Figure 9, the temperature at the location of tensile reinforcement ( $25 \mathrm{~mm}$ from the bottom) has exceeded this value from $1.5 \mathrm{~h}$ to $2 \mathrm{~h}$ of fire exposure. Thus, the damages of concrete and steel bars caused by high temperatures would lead to large deformations, as plotted in
Figure 11. As well known, the mechanical responses of the RC beam are highly dependent on the temperature distribution obtained from transient thermal analysis. A typical cross section of the RC beam is selected by neglecting longitudinal heat transfer, and thermal results are obtained by applying $2 \mathrm{D}$ thermal analysis. According to this simplification, differences between numerical prediction and experimental results might appear due to the errors cumulated from previous thermal analysis, especially under longtime fire exposure, for example, Figure 11 after $2 \mathrm{~h}$ exposure. Generally, the predicted data are consistent with the measured data.

Figure 12 shows the variation of ultimate load with the increase in fire duration. According to the proposed model, the residual load-carrying capacity progressively reduces to $50 \%$ of the unheated reference beam after approximately $2 \mathrm{~h}$ of exposure, which corresponds with the test data and FEM. To provide a quantitative overview of time-dependent stiffness, the secant stiffness, which is evaluated at $75 \%$ of 


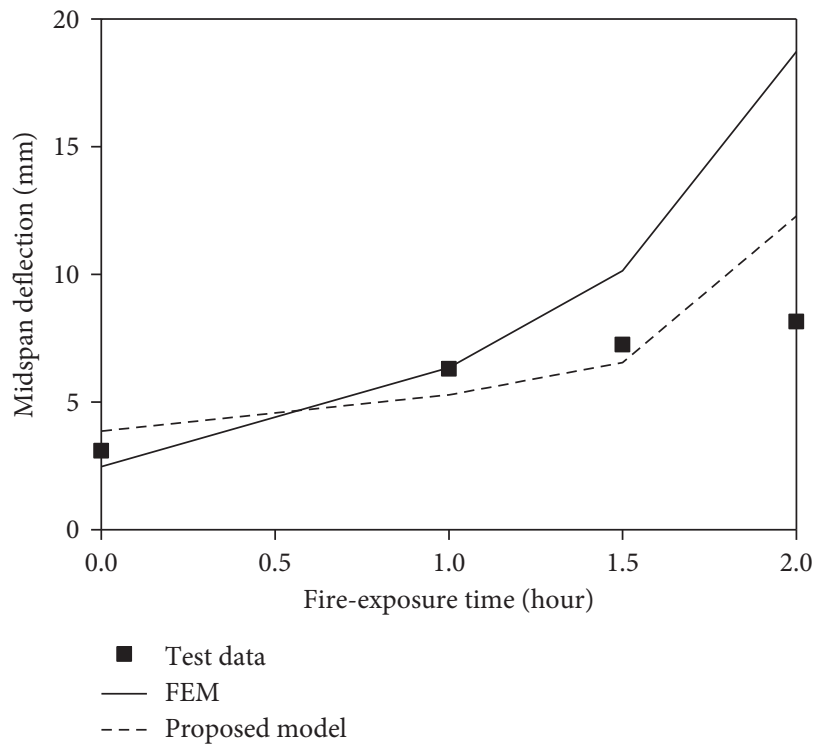

(a)

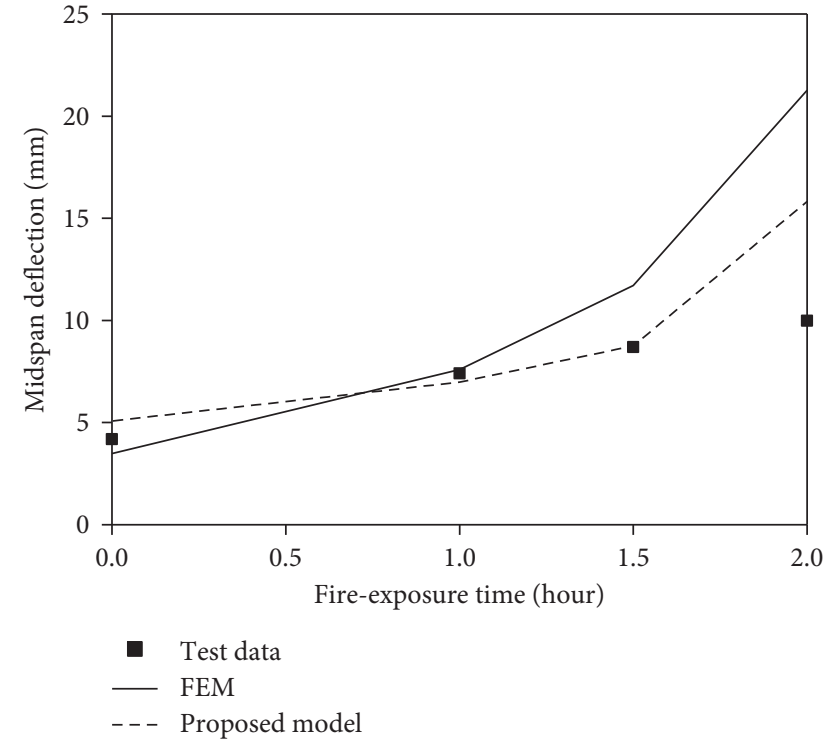

(b)

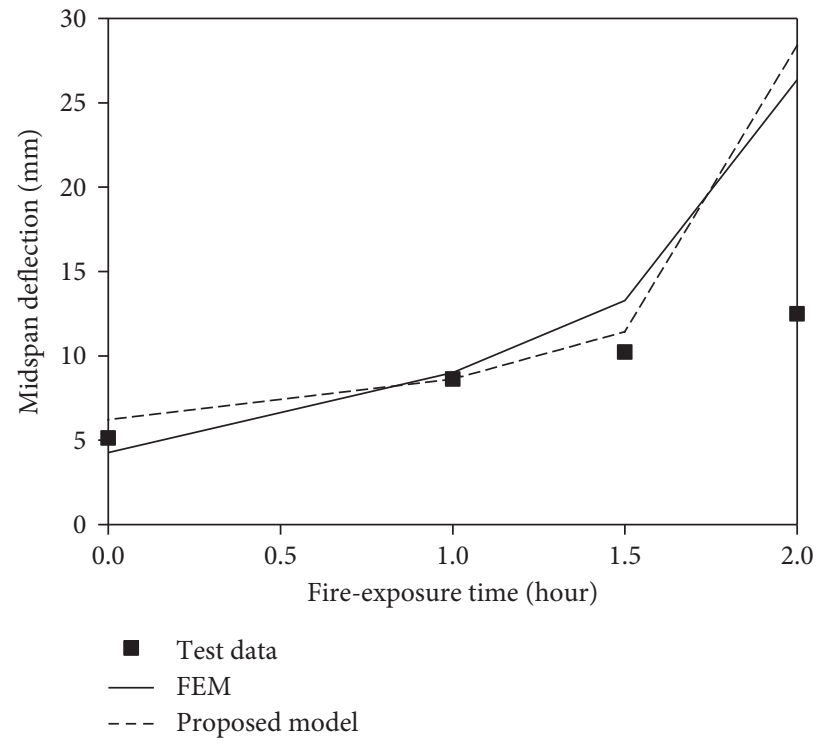

(c)

Figure 11: Fire exposure time-midspan deflection under external loadings: (a) $60 \mathrm{kN}$, (b) $70 \mathrm{kN}$, and (c) $80 \mathrm{kN}$.

the ultimate load of the RC beam, is plotted as a function of fire duration in Figure 13. Based on the predicted results, the secant stiffness is reduced to $77.3 \%$ and $56.5 \%$ of the unheated reference beam after fire duration of $1 \mathrm{~h}$ and $1.5 \mathrm{~h}$, respectively, which is consistent with the test data. Although its relative stiffness turns to be $39.9 \%$ after a fire duration of $2 \mathrm{~h}$, which is larger than the relative stiffness in the experimental tests, considering that the numerical results are highly dependent on the empirical model for material properties at elevated temperatures, it is very acceptable considering the fact that only 16 spectral elements are deployed in this study to determine the structural performances, and the results correspond quite well with the data obtained from the literature [23]. Therefore, the proposed numerical approach is a promising tool for appropriately modeling the mechanical behaviors of an $\mathrm{RC}$ beam at fire exposure due to its simplicity and efficiency.

\section{Conclusions}

This paper presents a one-dimensional spectral model for simulating the behavior of RC beams that are subjected to standard ISO 834 fire exposure. This model is cooperated with a transient thermal analysis by using a 2D FE model. The computational costs are significantly reduced since a limited number of elements were implemented under the framework of the proposed numerical approach in this study. The experimental data of four fire scenarios are utilized for comparison: no heating (reference beam), $1 \mathrm{~h}$, $1.5 \mathrm{~h}$, and $2 \mathrm{~h}$ heating, and four-point loading tests were 


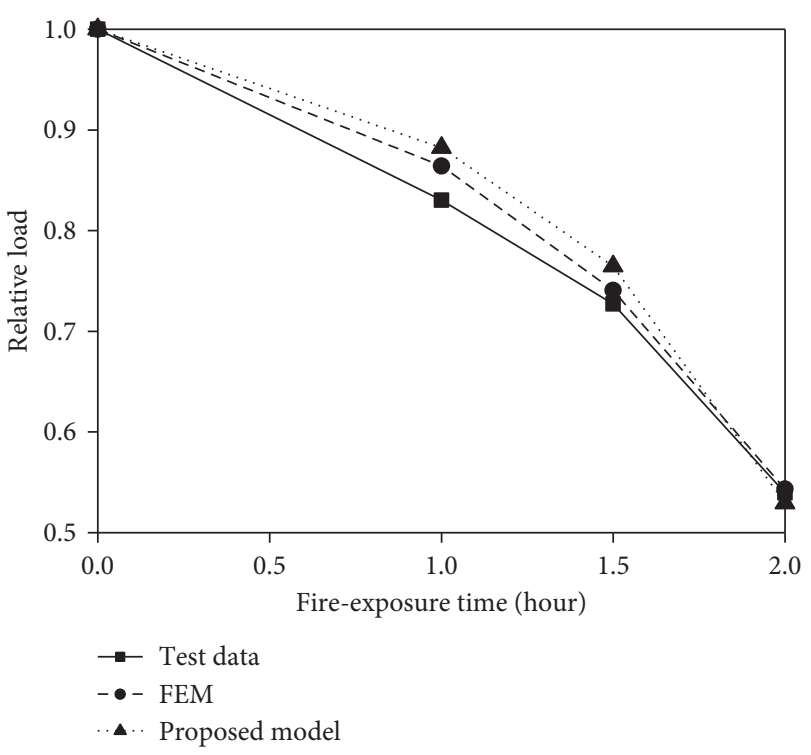

FIGURE 12: Ultimate load reduction.

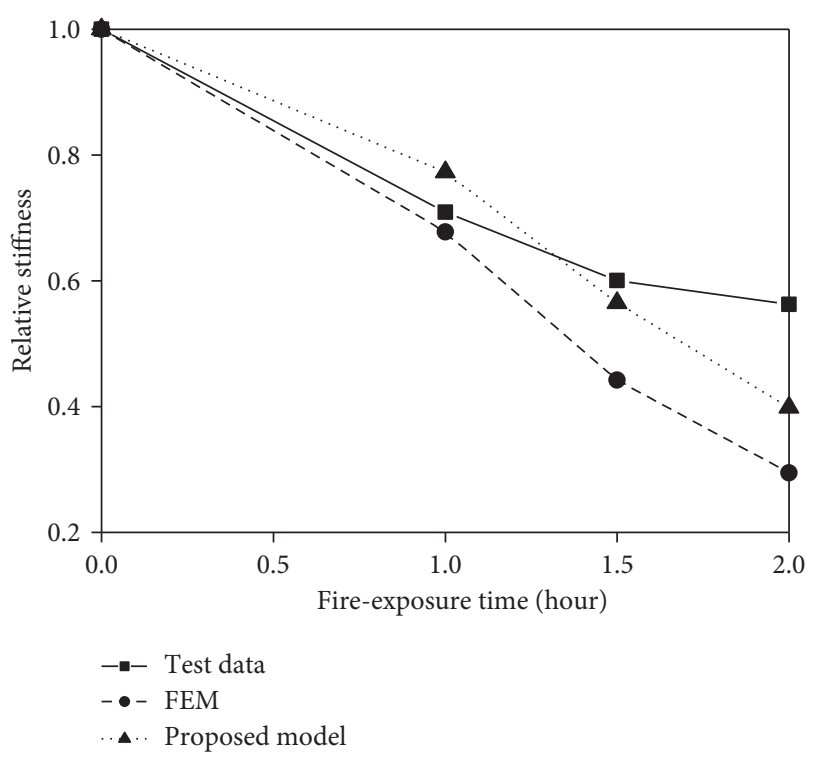

Figure 13: Secant stiffness reduction.

applied to the specimens after cooling down to obtain their mechanical responses after fire exposure. The results of a more complex FE model are also introduced to validate the accuracy and efficiency of the proposed model. Several conclusions can be drawn from this work in the following:

(1) One cross section of an RC beam was chosen to represent its typical thermal field using a $2 \mathrm{D}$ FE model, and the obtained temperature distribution agrees well with the results in the literature.

(2) A one-dimensional spectral model was developed to model the RC beam, which cooperates with the thermal distribution obtained from the $\mathrm{FE}$ analysis to calculate the structural behavior of an RC beam subjected to a four-point loading test for different levels of fire exposure.
(3) Few elements were deployed in the numerical simulation, since one element would be sufficient for modeling a section as long as its geometrical and material properties remain unchanged along the length of beam. The computational burdens are significantly reduced due to the simplicity of the proposed numerical approach compared with conventional FE model.

(4) The interfacial bond-slip behavior between concrete and steel reinforcement was disregarded in this study, and a perfect bond model was assumed to perform the numerical simulation in a simplified way. Despite this, the predicted results exhibit good agreement with the test data and FEM analysis, which validate the accuracy and capability of the proposed numerical approach.

(5) The predicted load-deflection curves are found to be in good agreement with the experimental and FEM data. The residual resistances and stiffness of the RC beam are quantitatively evaluated in this study, which demonstrate the damages of structures due to fire exposure.

\section{Data Availability}

The data used to support the findings of this study are included in the article.

\section{Conflicts of Interest}

The authors declare that they have no conflicts of interest.

\section{Acknowledgments}

The authors acknowledge the financial supports from the National Natural Science Foundation of China (Project no. 51708062), 111 Project of China (Grant no. B18062), Fundamental Research Funds for the Central Universities of China (Project nos. 106112016CDJXY200001 and 2018CDQYTM0044), and Spanish Ministry of Economy and Competitiveness (Project no. BIA2017-84975-C2-1-P).

\section{References}

[1] J. A. Purkiss, Fire Safety Engineering, Design of Structures, Butterworth Heinemann, Oxford, UK, 2nd edition, 2007.

[2] EN 1992-1-2, Eurocode 2: Design of Concrete Structures. Part 1-2: General Rules-Structural Fire Design, European Committee for Standardization, Brussels, Belgium, 2004.

[3] FIP/CEB, FIP/CEB Report on Methods of Assessment of the Fire Resistance of Concrete Structural Members, Cement and Concrete Association, Slough, UK, 2004.

[4] ACI 216.1, Code Requirements for Determining Fire Resistance of Concrete and Masonry Construction Assemblies, American Concrete Institute, Detroit, MI, USA, 2007.

[5] ISO 834-1, Fire Resistance Tests-Elements of Building Construction. Part 1: General Requirement, International Organization for Standardization, Geneva, Switzerland, 1999.

[6] Z. P. Bazant and M. F. Kaplan, Concrete at High Temperatures: Material Properties and Mathematical Models, Longman, Harlow, UK, 1996. 
[7] B. Zhang and N. Bicanic, "Residual fracture toughness of normal- and high-strength gravel concrete after heating to $600^{\circ}$ C," ACI Materials Journal, vol. 99, pp. 217-226, 2000.

[8] P. D. Morley and R. Royles, "Response of the bond in reinforced concrete to high temperature," Magazine of Concrete Research, vol. 35, no. 123, pp. 67-74, 1983.

[9] T. Pothisiri and P. Panedpojaman, "Modeling of bonding between steel rebar and concrete at elevated temperatures," Construction and Building Materials, vol. 27, no. 1, pp. 130140, 2012.

[10] V. K. R. Kodur and A. Agrawal, "Effect of temperature induced bond degradation on fire response of reinforced concrete beams," Engineering Structures, vol. 142, pp. 98-109, 2017.

[11] H. J. Wu, T. T. Lie, and J. Y. Hu, "Fire resistance of beam-slab specimens-experimental studies," Internal Report No. 641, Institute for Research in Construction, National Research Council Canada, Ottawa, ON, Canada, 1993.

[12] A. Kumar and V. Kumar, "Behaviour of RCC beams after exposure to elevated temperatures," Journal of the Institution of Engineers (India), Civil Engineering Division, vol. 84, pp. 165-170, 2003.

[13] M. B. Dwaikat and V. K. R. Kodur, "Response of restrained concrete beams under design fire exposure," Journal of Structural Engineering, vol. 135, no. 11, pp. 1408-1417, 2009.

[14] J.-r. Ren, H.-g. Chen, T. Sun, H. Song, and M.-s. Wang, "Flexural behaviour of combined FA/GGBFS geopolymer concrete beams after exposure to elevated temperatures," Advances in Materials Science and Engineering, vol. 2017, Article ID 6854043, 9 pages, 2017.

[15] B. Ellingwood and T. D. Lin, "Flexural and shear behaviour of concrete beams during fires," Journal of Structural Engineering, vol. 117 , no. 2, pp. 440-458, 1991.

[16] D. D. Capua and A. R. Mari, "Nonlinear analysis of reinforced concrete cross-sections exposed to fire," Fire Safety Journal, vol. 42, no. 2, pp. 139-149, 2007.

[17] J. H. Hsu and C. S. Lin, "Effect of fire on the residual mechanical properties and structural performance of reinforced concrete beams," Journal of Fire Protection Engineering, vol. 18, no. 4, pp. 245-274, 2008.

[18] V. R. Kodur and A. Agrawal, "An approach for evaluating residual capacity of reinforced concrete beams exposed to fire," Engineering Structures, vol. 110, pp. 293-306, 2016.

[19] S. Bratina, I. Planinc, M. Saje, and T. Goran, "Non-linear fireresistance analysis of reinforced concrete beams," Structural Engineering and Mechanics, vol. 16, no. 6, pp. 695-712, 2003.

[20] B. M. Luccioni, M. I. Figueroa, and R. F. Danesi, "Thermomechanic model for concrete exposed to elevated temperatures," Engineering Structures, vol. 25, no. 6, pp. 729-742, 2003.

[21] Z. H. Huang, I. W. Burgess, and R. J. Plank, “Threedimensional analysis of reinforced concrete beam-column structures in fire," Journal of Structural Engineering, vol. 135, no. 10, pp. 1201-1212, 2009.

[22] W. Y. Gao, J. G. Dai, J. G. Teng, and G. M. Chen, "Finite element modeling of reinforced concrete beams exposed to fire," Engineering Structures, vol. 52, pp. 488-501, 2013.

[23] J. Ozbolt, J. Bosnjak, G. Periskic, and A. Sharma, "3D numerical analysis of reinforced concrete beams exposed to elevated temperature," Engineering Structures, vol. 58, pp. 166-174, 2014.

[24] H. Dong, W. Cao, J. Bian, and J. Zhang, "The fire resistance performance of recycled aggregate concrete columns with different concrete compressive strengths," Materials, vol. 7, no. 12, pp. 7843-7860, 2014.

[25] V. K. R. Kodur, M. S. Dwaikat, and N. Raut, "Macroscopic FE model for tracing the fire response of reinforced concrete structures," Engineering Structures, vol. 31, no. 10, pp. 23682379, 2009.

[26] B. Wu and J. Z. Lu, "A numerical study of the behaviour of restrained RC beams at elevated temperatures," Fire Safety Journal, vol. 44, no. 4, pp. 522-531, 2009.

[27] R. Perera and D. Bueso-Inchausti, "A unified approach for the static and dynamic analyses of intermediate debonding in FRP-strengthened reinforced concrete beams," Composite Structures, vol. 92, no. 11, pp. 2728-2737, 2010.

[28] R. Sun, E. Sevillano, and R. Perera, "A discrete spectral model for intermediate crack debonding in FRP-strengthened RC beams," Composites Part B: Engineering, vol. 69, pp. 562-575, 2015.

[29] M. B. Dwaikat and V. K. R. Kodur, "A numerical approach for modeling the fire induced restraint effects in reinforced concrete beams," Fire Safety Journal, vol. 43, no. 4, pp. 291307, 2008.

[30] P. Bamonte and F. L. Monte, "Reinforced concrete columns exposed to standard fire: comparison among different constitutive models for concrete at high temperature," Fire Safety Journal, vol. 71, pp. 310-323, 2015.

[31] S. Bratina, B. Cas, M. Saje, and I. Planinc, "Numerical modelling of behaviour of reinforced concrete columns in fire and comparison with Eurocode 2," International Journal of Solids and Structures, vol. 42, no. 21-22, pp. 5715-5733, 2005.

[32] C. Lopez, J. P. Firmo, J. R. Correia, and C. Tiago, "Fire protection systems for reinforced concrete slabs strengthened with CFRP laminates," Construction and Building Materials, vol. 47, pp. 324-333, 2013.

[33] J. P. Firmo, M. R. T. Arruda, and J. R. Correia, "Numerical simulation of the fire behaviour of thermally insulated reinforced concrete beams strengthened with EBR-CFRP strips," Composite Structures, vol. 126, pp. 360-370, 2015.

[34] M. B. Dwaikat and V. K. R. Kodur, "Hydrothermal model for predicting fire-induced spalling in concrete structural systems," Fire Safety Journal, vol. 44, no. 3, pp. 425-434, 2009.

[35] M. Terro, "Numerical modeling of the behavior of concrete structures in fire," ACI Structural Journal, vol. 95, pp. 183192, 1998. 


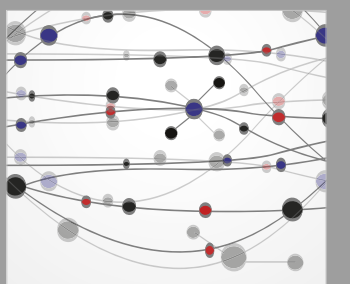

The Scientific World Journal
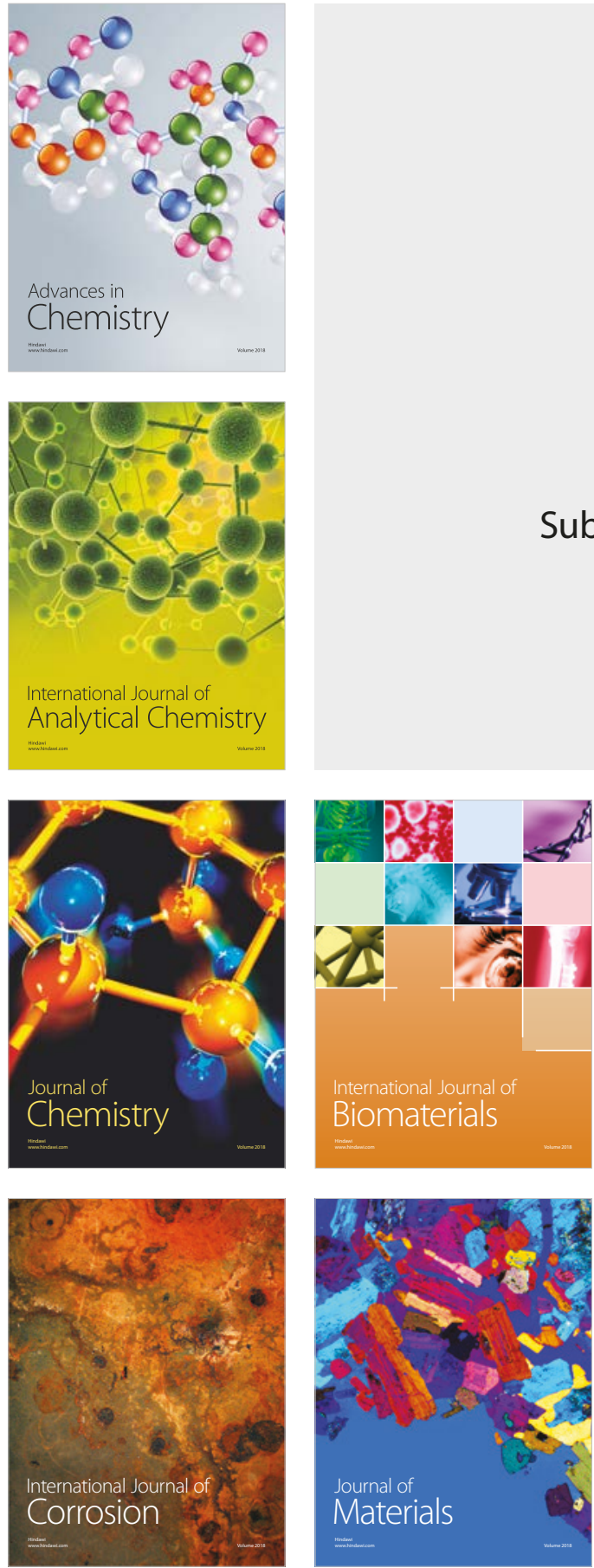

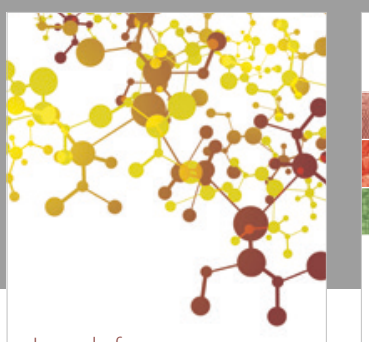

Journal of

Applied Chemistry
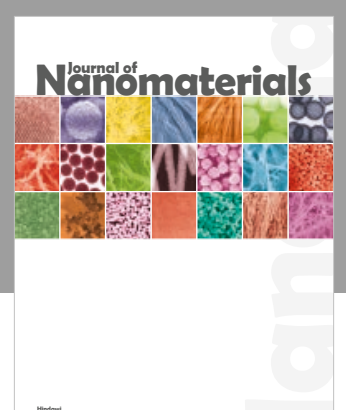

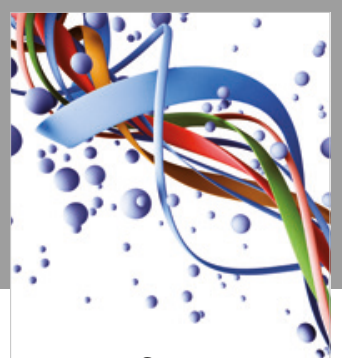

Scientifica

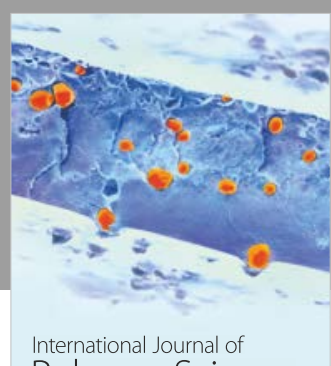

Polymer Science

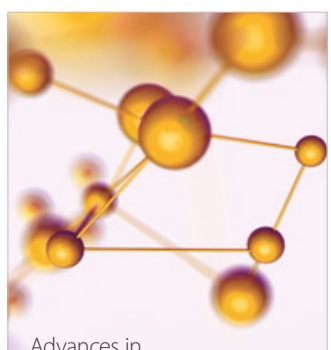

Physical Chemistry
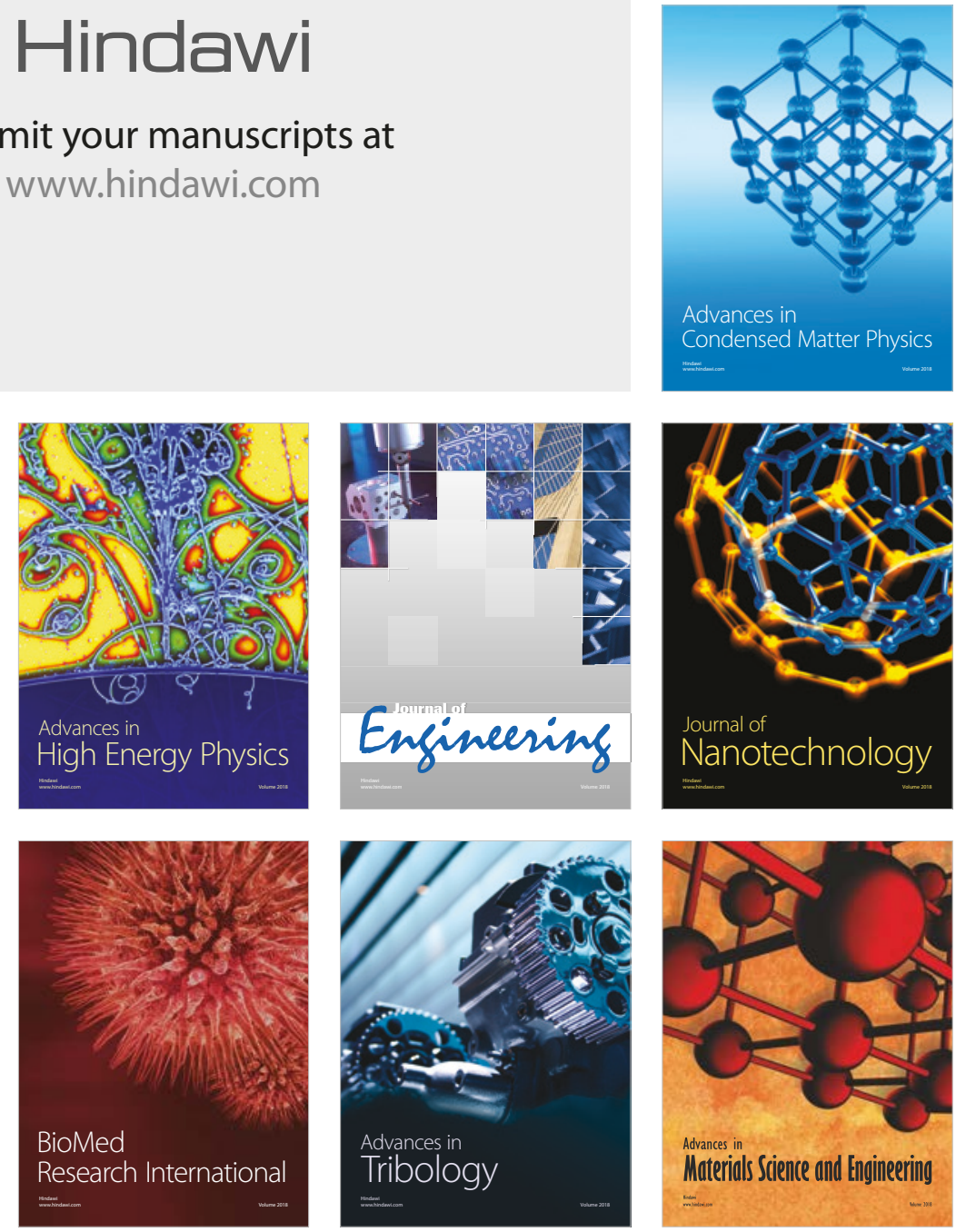